\title{
2017 IEEE International Symposium on Circuits and Systems (ISCAS) Proceedings
}

(c) 2017 IEEE. Personal use of this material is permitted. However, permission to reprint/republish this material for advertising or promotional purposes or for creating new collective works for resale or redistribution to servers or lists, or to reuse any copyrighted component of this work in other works must be obtained from the IEEE.

Additional copies may be ordered from:

IEEE Service Center

445 Hoes Lane

Piscataway, NJ 08855-1331 USA

+1800678 IEEE (+1 800678 4333)

$+17329811393$

+17329819667 (FAX)

email: customer-service@ieee.org

Copyright and Reprint Permission: Abstracting is permitted with credit to the source. Libraries are permitted to photocopy beyond the limit of U.S. copyright law, for private use of patrons, those articles in this volume that carry a code at the bottom of the first page, provided that the per-copy fee indicated in the code is paid through the Copyright Clearance Center, 222 Rosewood Drive, Danvers, MA 01923. Other copy, reprint, or reproduction requests should be addressed to IEEE Copyrights Manager, IEEE Service Center, 445 Hoes Lane, P.O. Box 1331, Piscataway, NJ 08855-1331. All rights reserved. Copyright $@ 2011$ by the Institute of Electrical and Electronics Engineers, Inc.

IEEE Catalog Number: CFP17ISC-USB

ISBN: 978-1-4673-6852-0 